\title{
0 Primeiro Vestibular Indígena na UFPR
}

Ciméa Barbato Bevilaqua Como parte de uma política mais geral de ações afirmativas, a Universidade Federal

UFPR do Paraná passou a destinar em 2005 vagas específicas para estudantes indígenas em seus cursos de graduação, em caráter suplementar às que são ofertadas regularmente. O cronograma definido pela Resolução n 37/04 do Conselho Universitário prevê a oferta de cinco vagas para indígenas em 2005 e 2006, sete vagas em 2007 e 2008, e dez vagas anuais a partir de 2009, a serem preenchidas a partir de processo seletivo diferenciado e exclusivo.

Por meio de um convênio firmado com a Secretaria de Estado da Ciência, Tecnologia e Ensino Superior (SETI), o processo seletivo para a ocupação das cinco vagas previstas para 2005 foi realizado em conjunto com as seis universidades públicas do Paraná ${ }^{1}$, nas quais o ingresso de estudantes indígenas vem ocorrendo desde 2002, nos termos da Lei Estadual no 13.134. Resguardadas algumas diferenças existentes entre a legislação estadual e as normas da UFPR, o convênio permitiu que as instituições envolvidas definissem conjuntamente todas as providências para a realização do vestibular indígena. O processo foi coordenado pela Comissão Universidade para os Índios (CUIA), formada por três representantes de cada instituição².

As inscrições foram realizadas de 9 de novembro a 10 de dezembro de 2004. Enquanto as vagas nas instituições estaduais se destinam apenas a candidatos procedentes de áreas indígenas no Paraná ${ }^{3}$, a UFPR não estabeleceu restrições quanto à residência dos candidatos, desde que em território brasileiro. Desse modo, os estudantes indígenas residentes no Paraná tiveram sete opções de inscrição no vestibular unificado (as seis universidades estaduais e a UFPR). Já os candidatos provenientes dos demais estados puderam concorrer somente às vagas da UFPR. 
Além dos documentos pessoais e do certificado de conclusão do ensino médio, o candidato deveria apresentar uma carta de recomendação assinada conjuntamente pela liderança de sua aldeia e pela FUNAI. Para candidatos residentes em áreas urbanas era necessária apenas a recomendação da FUNAI.

A UFPR recebeu 75 candidatos, que se inscreveram para 22 cursos de graduação. Os cursos com maior número de inscritos foram Medicina, Odontologia, Enfermagem, Administração, Agronomia, Direito e Educação Física. Embora a maior parte dos candidatos fosse procedente da Região Sul, também participaram do processo seletivo estudantes indígenas oriundos do Amazonas, Pará e Mato Grosso do Sul, pertencentes a sete etnias (ver tabelas ao final do texto).

As provas foram realizadas de 18 a 20 de janeiro na Universidade Estadual de Maringá, escolhida como sede do vestibular unificado de 2005. Tal como no vestibular regular, as questões do vestibular indígena tiveram por base os conteúdos curriculares do ensino médio, abrangendo as disciplinas de língua portuguesa, língua estrangeira moderna (inglês ou espanhol), matemática, física, química, biologia, geografia e história. A principal diferença em relação ao vestibular regular foi a realização de uma prova oral de língua portuguesa, além da prova de redação. O histórico escolar do ensino médio também foi levado em conta para o cálculo final das notas.

Conforme vinha ocorrendo desde a implantação do vestibular específico nas universidades estaduais do Paraná, em 2002, o processo seletivo de 2005 não previu nenhum mecanismo para favorecer ou limitar o ingresso em determinados cursos. Uma vez que as vagas ofertadas se destinam ao atendimento das demandas das próprias sociedades indígenas, os candidatos foram classificados numa lista única, conforme o desempenho nas provas, observando-se para a matrícula a universidade e o curso escolhido no momento da inscrição.

Nos anos anteriores, o ingresso de estudantes indígenas nas universidades estaduais havia mantido uma distribuição uniforme por áreas de conhecimento e cursos. Na primeira participação da Universidade Federal do Paraná no processo, porém, o resultado do vestibular específico revelou uma concentração dos candidatos de melhor desempenho: os cinco estudantes indígenas aprovados para a UFPR ingressaram no curso de Medicina. Quatro deles começaram a freqüentar as aulas no primeiro semestre, estando previsto para o segundo semestre o ingresso de mais uma estudante ${ }^{4}$.

Ainda no que diz respeito ao resultado do vestibular específico, outro ponto merece consideração. A participação da UFPR no processo ofereceu, pela primeira vez, a possibilidade de comparação entre o desempenho dos estudantes indígenas residentes no Paraná e o de candidatos procedentes de outras regiões do país. Evidenciouse assim a desigualdade da formação escolar indígena nas diferentes unidades da federação. Os candidatos procedentes do Rio Grande do Sul foram, em conjunto, os que tiveram melhor desempenho relativo. E, em termos mais gerais, os candidatos residentes fora do Paraná obtiveram médias superiores às dos candidatos do Paraná, resguardadas exceções individuais. 
Tão importante quanto o ingresso de estudantes indígenas na universidade é a garantia de sua permanência até a conclusão do curso escolhido. A resolução do Conselho Universitário da UFPR que estabeleceu vagas para estudantes indígenas também previu a implantação de um programa de acompanhamento, em parceria com a FUNAl, para garantir condições adequadas de subsistência aos estudantes indígenas durante todo o período de integralização curricular, além de apoio pedagógico e administrativo

Sob este aspecto, ainda há muito a ser feito. A partir de entendimentos iniciados em 2004 entre a Reitoria da UFPR e a Coordenação Geral de Educação da FUNAl, cada uma das instituições assumiu parte dos compromissos relativos à permanência dos estudantes indígenas (moradia, transporte, alimentação, material didático etc.). Até o momento, porém, não houve a assinatura de um convênio que assegure a continuidade do programa. Também os procedimentos internos de acompanhamento dos estudantes indígenas na UFPR ainda dependem de maior formalização, a fim de que o ingresso de alunos por meio do vestibular específico possa ter continuidade nos próximos anos conforme o cronograma e as condições inicialmente previstas pelo Conselho Universitário.

As tabelas a seguir foram elaboradas a partir das fichas de inscrição ao vestibular indígena de 2005.

Inscrições para o Vestibular Indígena 2005

\begin{tabular}{lccc}
\hline \multicolumn{1}{c}{ UNIVERSIDADE } & INSCRITOS & VAGAS & $\begin{array}{c}\text { RELAÇÃO } \\
\text { candidato/vaga }\end{array}$ \\
\hline Universidades Estaduais do Paraná* & 65 & $18^{* *}$ & 3,61 \\
\hline Universidade Federal do Paraná & 75 & 5 & 15 \\
\hline Total & 140 & 23 & - \\
\hline
\end{tabular}

* UEL, UEM, UEPG, UNESPAR, UNIOESTE e UNICENTRO.

** Três vagas por instituição. 
Ciméa Barbato Bevilaqua

\begin{tabular}{lc}
\multicolumn{2}{c}{ Inscritos para a UFPR por etnia } \\
\hline ETNIA & $\mathbf{N}^{\circ}$ DE INSCRITOS \\
\hline Gavião & 3 \\
\hline Guarani & 5 \\
\hline Kaingang & 36 \\
\hline Kanamari & 1 \\
\hline Terena & 3 \\
\hline Ticuna & 20 \\
\hline Tucano & 1 \\
\hline Sem informação & 6 \\
\hline
\end{tabular}

Inscritos para a UFPR por procedência

\begin{tabular}{lc}
\hline ESTADO DE ORIGEM & INSCRITOS \\
\hline Amazonas & 21 \\
\hline Mato Grosso do Sul & 4 \\
\hline Pará & 3 \\
\hline Paraná & 10 \\
\hline Rio Grande do Sul & 23 \\
\hline Santa Catarina & 14 \\
\hline Total & 75 \\
\hline
\end{tabular}

\begin{tabular}{lc}
\multicolumn{2}{c}{ Cursos de maior procura na UFPR } \\
\hline CURSO & INSCRITOS \\
\hline Medicina & 10 \\
\hline Odontologia & 9 \\
\hline Enfermagem & 9 \\
\hline Administração & 6 \\
\hline Agronomia & 6 \\
\hline Direito & 5 \\
\hline Educação Física & 5 \\
\hline
\end{tabular}

Ciméa Barbato Bevilaqua é professora do Departamento de Antropologia da UFPR e participou da 


\section{NOTAS}

1 Universidade Estadual de Maringá (UEM), Universidade Estadual de Londrina (UEL), Universidade Estadual de Ponta Grossa (UEPG), Universidade Estadual do Oeste do Paraná (Unioeste - Cascavel), Universidade Estadual do Centro-Oeste (Unicentro - Guarapuava) e Universidade Estadual do Paraná (Unespar - Jacarezinho).

2 Pela UFPR, participaram os professores Ciméa Barbato Bevilaqua, Edilene Coffaci de Lima e Ricardo Cid Fernandes, do Departamento de Antropologia.

3 A Lei no 13.134, de 18/04/2001, prevê que cada universidade estadual do Paraná destine anualmente três vagas específicas para indígenas que residam ou tenham residido em aldeias situadas no Estado por pelo menos dois anos.

4 Os quatro alunos indígenas que já ingressaram na UFPR são: Eva Simone da Silva (de etnia kaingang, procedente da Terra Indígena Nonoai-RS), os irmãos Alvandi Salles Ribeiro e Caritiana Salles Ribeiro (kaingang, T.l. Guarita-RS) e Luciene Paiva Flores (terena, residente em Curitiba). No segundo semestre, deverá ingressar a estudante Morgana de Freitas Pandolfo (kaingang, residente em Passo Fundo-RS). 